\title{
Effectiveness of multiple-capture live traps for field behavioral studies of microtine rodents
}

\author{
LOWELL L. GETZ \\ University of Illinois, Urbana, Illinois \\ F. RUSSELL COLE \\ Colby College, Waterville, Maine \\ and \\ LOUIS VERNER \\ Illinois Wesleyan University, Bloomington, Illinois
}

\begin{abstract}
Use of multiple-capture live traps in routine demographic studies provides data concerning social organization and potential interactions between individuals, data not otherwise available from single-capture traps. Multiple-capture traps are especially effective in field behavioral studies in which large numbers of animals occupying a single nest must be monitored at frequent intervals. Burt multiple-capture traps are shown to be at least as efficient as Longworth single-capture treadle traps in capturing both Microtus ochrogaster and Microtus pennsylvanicus.
\end{abstract}

The authors have successfully used Burt-type multiplecapture live traps (Burt, 1940) in a number of population studies of Microtus (Cole \& Batzli, 1978; Getz, 1960; Getz, Verner, Cole, Hofmann, \& Avalos, 1979; Verner $\&$ Getz, 1985). Multiple-capture live traps provide data concerning social organization and potential interactions between individuals, data not readily available from single-capture traps (Getz, 1972; Getz, Carter, \& Gavish, 1981; Reich \& Tamarin, 1984). Thus, use of multiplecapture live traps increases the potential "return" from population studies. Multiple-capture data from demographic studies using single-capture treadle traps have been used to describe social organization within a population (Blaustein \& Rothstein, 1978; Jenkins \& Llewellyn, 1981; Novak, 1983; Petersen, 1975). However, multiple captures in single-capture traps are obviously relatively infrequent in comparison to those in multiple-capture traps.

Multiple-capture live traps have been especially useful in studies emphasizing social organization of free-living populations of small mammals (Getz \& Hofmann, in press). In such studies, it often is necessary to monitor at frequent intervals all inhabitants of given nests by livetrapping. When nests contain large numbers of individuals and/or receive numerous visitors (Frank, 1957; Getz \& Hofmann, in press; Wolff, 1980), single-capture live traps are not satisfactory. Ensuring capture of all nest

This research was supported by NIH Grant No. HD 09328 to L. L. Getz. Reprint requests should be sent to L. L. Getz, Department of Ecology, Ethology, and Evolution, University of Illinois, $505 \mathrm{~S}$. Goodwin, Urbana, IL 61801 . inhibitants at frequent intervals often requires more singlecapture traps than can be practically placed around the nest site and still allow unrestricted movement of individuals to and from the nest. When using multiplecapture live traps, we have been able to monitor up to 20 individuals at a nest by use of only 4-5 traps; it is not unusual to capture 6-10 individuals in one trap, even when the traps are checked at 2-3-hr intervals.

The Burt multiple-capture live trap utilizes a 2.5-3.0$\mathrm{cm}$ wide metal runway, fitted with a sloping gravitycontrolled door, inserted into the front of the trap. The animals lift the door with their heads and shoulders to enter the trap. The remainder of the front of the trap is covered with $0.5-\mathrm{cm}$ mesh hardware cloth. Traps made of $1.25-\mathrm{cm}$ redwood reduce winter mortality; such traps do not have to be provided with cotton or other nest material.

Mihok, Boonstra, Rood, and Schwartz (1982) questioned the efficiency of this type of multiple-capture live trap in capturing meadow voles, Microtus pennsylvanicus. They presented evidence that Longworth singlecapture treadle live traps were more effective in capturing individuals of this species than were multiple-capture traps. These authors concluded that $M$. pennsylvanicus avoid multiple-capture traps. Accordingly, they questioned the advisability of using Burt multiple-capture live traps in population studies. Mihok et al. (1982) noted, however, that there is little quantitative data available regarding the relative efficiency of multiple-capture and single-capture traps in sampling given species of small mammals. Other workers also have indicated to us that they have not been satisfied with the capture success of Burt multiple-capture traps. (Comparative data have not 
been published, however.) The Longworth single-capture live trap remains the trap most commonly used by individuals studying Microtus.

This note presents comparative data regarding efficiency of Burt multiple-capture and Longworth single-capture live traps in capturing the meadow vole, $M$. pennsylvanicus, and the prairie vole, Microtus ochrogaster, and demonstrates effectiveness of the former trap for field behavioral studies as well as for demographic studies.

\section{TRAPPING}

\section{Microtus ochrogaster}

Efficiency of the Burt trap in capturing $M$. ochrogaster was compared with that of the Longworth trap in a 1.4ha alfalfa field near Urbana, Illinois. The area was gridded at a $10-\mathrm{m}$ interval (140 trap stations). The area was trapped from July 10-12, 1975, with one Burt trap at each station. The area was then trapped July 16-18 with one Longworth trap at each station. The traps were checked early morning and late afternoon. All animals were marked by toe clipping. (For additional details of the methods and description of the study area, see Getz et al., 1979.)

The $M$. ochrogaster population in the area was in the increase phase of the population cycle; the population had increased from only 3 individuals in mid-June 1975. During the July 10-12 trapping with Burt live traps, $22 \mathrm{M}$. ochrogaster were captured a total of 51 times. Twenty-four individuals were captured a total of 50 times when the area was trapped July 16-18 with Longworth traps. Three unmarked animals ( 2 subadults, 1 adult) and 4 marked dispersers from an adjacent study area were caught in the Longworth traps; 4 of the new animals were captured in the border grid stations. Two voles caught during July 10-12 in Burt traps, but not caught in the Longworth traps, were caught when the area was trapped again with Burt traps August 16-18.

New captures in the Burt traps on July 10,11, and 12 were 10,7 , and 2 , respectively; daily captures of new animals in Longworth traps on July 16, 17, and 18 were 4,2 , and 1 , respectively.

\section{Microtus pennsylvanicus}

Efficiency of the Burt trap in capturing $M$. pennsylvanicus was compared with that of the Longworth trap in two 0.5-ha areas within a 3-ha restored tall grass prairie near Urbana, Illinois. The areas were gridded at a $10-\mathrm{m}$ interval (49 stations in each area) and live trapped with one Burt live trap at each station from April, 13-15, 1983. The methods were the same as those used in the alfalfa study area. Following the last check of the Burt traps on the afternoon of April 15, one Longworth trap was set at each station. These traps were checked morning and afternoon from April 16 to 18.

Ninety-four M. pennsylvanicus were captured a total of 185 times when the two areas were trapped with Burt traps. Thirty-nine of the voles were new (the areas had been previously trapped with Burt traps March 16-18, 1983). Forty-four individuals were caught a total of 58 times when the areas were trapped April 16-18 with Longworth traps. Eleven unmarked $M$. pennsylvanicus were captured during the trapping with Longworth traps. Three 9-g unmarked young were captured at one station; all but 1 of the remaining new voles (adults and subadults) were captured at border stations. Eleven $M$. pennsylvanicus caught in Burt traps April 13-15, but not caught in the Longworth traps, were captured when the areas were trapped with Burt traps May 11-13, 1983.

The number of captures of unmarked animals in the Burt traps on April 13, 14, and 15 were 23, 7, and 9, respectively. Daily captures of unmarked animals in the Longworth traps on April 16, 17, and 18 were 3, 6, and 4, respectively.

\section{DISCUSSION}

In our trials, the Burt multiple-capture live trap was equally or more effective in capturing $M$. ochrogaster and $M$. pennsylvanicus than were the Longworth single-capture treadle traps.

Daily captures of new animals in Longworth traps following 3 days of trapping in an area with Burt traps were essentially the same as those on the last 2 days of trapping with Burt traps. Unmarked animals caught in the Longworth traps most likely represented new recruits into the area (via birth or dispersal) or animals whose home ranges were only partly within the study area and who had not encountered a trap during trapping with Burt traps. In addition, some previously marked animals were not caught in Longworth traps, but were captured in subsequent trappings with Burt live traps.

The contradictory results from our field trials on Microtus and those of Mihok et al. (1982) most likely result from the difference in the methods employed. The latter placed both a multiple-capture and Longworth trap at each station and apparently did not prebait. We set only one type of trap at a given station and we prebaited. The observation of Mihok et al. (1982) that, although both traps were investigated, more voles were caught in the Longworth traps, suggests that given a choice the voles will enter Longworth traps more readily than they will enter multiple-capture traps. From our data, however, it appears that if only a multiple-capture trap is present, the voles will enter this type of trap as readily as they will enter a Longworth trap. Trapability (percent of the individuals known to be present that were captured during a given trapping session) of Microtus ranged from $67-100 \%$ when multiplecapture traps were used (Getz et al., 1979). These values were essentially the same as those recorded for the same two species when Longworth traps were used (Krebs, Keller, \& Tamarin, 1969).

Mihok et al. (1982) did not indicate that the traps in their primary study were prebaited. When prebaiting was employed in a preliminary study, mixed results were obtained. Prebaiting undoubtedly is important in attracting voles to the trap and in providing an incentive for them to enter the trap. One of us (F.R.C.) has noted that in small enclosure studies, Microtus were more readily captured in Longworth traps than in Burt traps when the traps were not prebaited. When prebaited for 2 days, there was no difference in capture efficiency of Longworth and Burt traps.

Familiarity with a given type of live trap may be partially responsible for the different results various workers have observed when testing effectiveness of multiple-capture live traps. If a new type of trap is tested during an ongoing study, the small mammals may be at first somewhat reluctant to enter such a trap. This reluctance appears especially applicable to the multiple-capture trap because of the necessity for the animals to lift the door in order to enter the trap. However, once the animals become accustomed to entering a multiple-capture trap, they 
do so readily. Prebaiting serves to attract the animals to the traps and to entice them to enter the trap when it is set. As a result, it is important that there be a prebaiting period when using multiple-capture traps, if there is a relatively long time between trapping periods.

Mortality or injuries resulting from fighting within a trap are extremely rare. We have observed less than one instance of death or injury in at least 1,000 multiple captures for both species, even though $M$. pennsylvanicus displays high levels of intraspecific aggressiveness (Getz, 1962). There is opportunity for communication through the wire mesh front of the trap, and the second animal attempting to enter the trap can retreat before the door closes, if there is aggressive interaction with the animal already in the trap. Because individuals can reject subsequent arrivals and new arrivals can avoid entering an occupied trap, there is also a low probability of reduced reproductive success of females owing to pregnancy block during multiple captures (Bruce, 1959).

In conclusion, the Burt-type multiple-capture live trap is effective for use with $M$. ochrogaster and $M$. pennsylvanicus. Our data indicate that, if properly used, the trap is as effective as the Longworth single-capture treadle trap in capturing both species. The additional social organization data that may be obtained by use of multiple-capture traps warrant consideration for their use in routine demographic studies as well as in field behavioral studies.

\section{REFERENCES}

Blaustein, A. R., \& Rothstein, S. I., (1978). Multiple captures of Reithrodontomys megalotis: Social bonding in a mouse? American Midland Naturalist, 100, 376-383.

BRUCE, H. M. (1959). An exteroceptive block to pregnancy in the mouse. Nature, 184, 105.

BURT, W. N. (1940). Territorial behavior and populations of some small mammals in southern Michigan. Miscellaneous Publication Museum Zoology, University of Michigan, 45, 1-58.

Cole, F. R., \& BATZLI, G. O. (1978). The influence of supplemental feeding on a vole population. Journal of Mammalogy, 59, 809-819.

Frank, F. (1957). The causality of microtine cycles in Germany. Journal of Wildlife Management, 21, 113-121.

GetZ, L. L. (1960). A population study of the vole, Microtus pennsylvanicus. American Midland Naturalist, 64, 392-405.
GetZ, L. L. (1962). Aggressive behavior of the meadow and prairie voles. Journal of Mammalogy, 43, 351-358.

GETZ, L. L. (1972). Social structure and aggressive behavior in a population of Microtus pennsylvanicus. Journal of Mammalogy, 53, 310-317.

GetZ, L. L., Carter, C. S., \& Gavish, L. (1981). The mating system of the prairie vole, Microtus ochrogaster. Behavioral Ecology and Sociobiology, 8, 189-194.

Getz, L. L., \& HofmanN, J. E. (in press). Social organization in freeliving prairie voles, Microtus ochrogaster. Behavioral Ecology and Sociobiology.

Getz, L. L., Verner, L., Cole, F. R., Hofmann, J. E., \& Avalos, D. E. (1979). Comparisons of population demography of Microtus ochrogaster and M. pennsylvanicus. Acta Theriologica, 24, 319-349.

Jenkins, S. H., \& Llewellyn, J. B. (1981). Multiple captures of Peromyscus: Age, sex and species differences. Journal of Mammalogy, 62, 639-641.

Krebs, C. J., Keller, B. L., \& TAmarin, R. H. (1969). Microtus population biology: Demographic changes in fluctuating populations of $M$. ochrogaster and $M$. pennsylvanicus in southern Indiana. Ecology, 50, 587-607.

Minok, S., Boonstra, R., Rood, F. H., \& Schwartz, B. (1982). Response of Microtus pennsylvanicus to multiple-capture traps. Canadian Journal Zoology, 60, 2965-2967.

NovaK, J. M. (1983). Multiple captures of Peromyscus leucopus: social behavior in a small rodent. Journal of Mammalogy, 64, 710-713.

Petersen, M. K. (1975). An analysis of multiple captures in several rodents from Durango, Mexico. Journal of Mammalogy, 56, 703-705.

REICH, L. M., \& TAMARIN, R. H. (1984). Multiple-capture trap associations of meadow voles (Microtus pennsylvanicus). Journal of Mammalogy, 65, 85-90.

VERNER, L., \& GETZ, L. L. (1985). Significance of dispersal in fluctuating populations of Microtus ochrogaster and M. pennsylvanicus. Journal of Mammalogy, 66, 338-347.

WolfF, J. O. (1980). Social organization of the taiga vole (Microtus xanthognathus). The Biologist, 62, 34-45.

(Manuscript received for publication September 20, 1985.) 